\title{
Los oficiales reales de Quito bajo sospecha: el impago del situado y la propuesta de visita de la Caja (1712-1718) $1 /$
}

\author{
Quito's royal officials under suspicion: \\ the non-payment of the situado and the proposal \\ of an inspection of the Caja (1712-1718)
}

Carmen Ruigómez Gómez

Universidad Complutense, Madrid

Hasta 1712 la Caja de Quito cumplió regularmente con la obligación de enviar el situado a los presidios de Cartagena y Santa Marta. A partir de entonces, los oficiales reales se encontraron con grandes dificultades para satisfacerlo y escribieron al rey con la esperanza de que, ante la crisis que vivía la región, les liberara de tan pesada carga. En España, el Consejo de Indias analizó los argumentos y las cuentas presentadas por los oficiales reales quiteños y no sólo no les dispensó de enviar el situado, sino que concluyó que era necesaria una visita urgente a la Caja, que finalmente no se produjo.

Palabras Clave: Economía; Real Hacienda; Administración; Audiencia de Quito; Situado; Siglo XVIII.

Until 1712 the royal treasury in Quito regularly fulfilled its obligation to send the situado (annual subsidy) to the fortresses at Cartagena and Santa Marta. From that date onwards, the royal officials faced great difficulties in trying to do their job and they wrote to the king in the hope that, in view of the general economic crisis that the region was suffering, he would free them from such a heavy burden. In Spain, the Council of the Indies analyzed the arguments and the accounts presented by Quito's royal officials, and not only excused them from sending the situado, but concluded that an urgent visit to that city's treasury was needed. In the end, however, no inspection was carried out.

KeYwords: Economy; Royal Treasury; Administration; Quito's Audiencia; Situado; Eighteenth century.

1 Este trabajo es resultado del Proyecto de Investigación I+D+I, concedido por el Ministerio de Ciencia e Innovación, con número de referencia HAR2009-10094. 
Es una realidad conocida que la región serrana de la Audiencia de Quito, con su capital a la cabeza, padeció una profunda crisis económica desde finales del siglo XVII y, sobre todo, en las décadas iniciales de la centuria siguiente. Para explicar esta realidad, la historiografía se ha ocupado fundamentalmente de analizar la caída de la producción y comercio de textiles quiteños, principal activo económico de la región desde el siglo XVI. Distintos investigadores han analizado la prohibición de la mita de obrajes en 1701 y 1704, la disminución de la mano de obra por epidemias, hambrunas y huídas de indios ante el aumento de la presión fiscal, o la creciente demanda de tejidos de algodón frente a los de lana, y la repercusión que todos estos hechos tuvieron en el cierre de muchos obrajes de la región norte de la Audiencia quiteña. Otros historiadores han estudiado las consecuencias que para la economía de Quito, desde finales del siglo XVII, tuvo la presencia y actividad de los corsarios y comerciantes franceses que inundaron las costas del Pacífico de géneros europeos, contra los que los paños quiteños no pudieron competir.

Sea por unas razones o por otras, o mejor por una combinación de todas ellas, los primeros años del siglo XVIII fueron económica y financieramente muy complicados en el distrito de la Audiencia quiteña, una de cuyas evidencias fue la de escasez de moneda en la región. En este trabajo nos vamos a ocupar de cómo los oficiales reales quiteños gestionaron la Caja Real en esta época de crisis y, especialmente, de cómo intentaron justificar el incumplimiento de uno de sus principales deberes: el envío del situado a los presidios de Cartagena y Santa Marta, que era una carga muy gravosa para la Caja ya que suponía en torno al $40 \%$ de sus salidas.

\section{La Caja de Quito y sus gestores}

En el territorio de la Audiencia de Quito había cuatro Cajas Reales: Quito, Guayaquil, Loja y Zamora y la de Popayán. La de Quito estaba integrada por los corregimientos de Quito, Latacunga, Riobamba (con el asiento de Ambato), Chimbo, Otavalo y la villa de San Miguel de Ibarra, y por los gobiernos de Quijos y Macas y Jíbaros y Maynas. ${ }^{2}$ Entre 1712 y 1718, al frente de la Caja de Quito estuvieron el contador Diego Suárez de Figueroa y el tesorero Fernando García Aguado.

2 Archivo General de Indias (AGI), Quito, 134, sin f., plan de gastos de la Caja de Quito que hizo Dionisio de Alcedo el 20 de mayo de 1740, a petición de la Cámara del Consejo de Indias. 
Suárez de Figueroa había comprado el cargo en 1688 para su hijo José, entonces menor, con la cláusula de poder ejercer él mismo el oficio - lo que hizo a partir de agosto de ese año-, hasta que el niño alcanzara la mayoría de edad. En 1706 se inició un largo pleito entre padre e hijo por la posesión del oficio, que no terminó hasta 1721 en que se sentenció a favor de José. ${ }^{3}$ Mientras tanto Diego ejerció el cargo y así, en 1712, llevaba más de veinte años gestionando la Caja de Quito. En 1711, el conde de Selvaflorida inició una visita a la Caja, encargada por el virrey de Lima, que concluyó en 1714 con sentencia desfavorable tanto para el contador como para su anterior compañero, el tesorero Jacinto Salazar y Betancourt. Como consecuencia, Diego Suárez de Figueroa estuvo suspendido del oficio entre julio de 1714 y marzo de 1715 y definitivamente, por orden del Tribunal de Cuentas de Lima, a partir de enero de 1718.

Fernando García Aguado remató el ofició de tesorero en Lima y empezó a ejercer en febrero de 1711, sin ninguna experiencia previa en labores de Real Hacienda. Tenemos así dos perfiles muy distintos: por una parte, el contador, un hombre curtido en el oficio, que se resistía a abandonar en manos de su hijo, pero intimidado por una visita de la que no saldría bien parado; por otra, el tesorero, inexperto pero sagaz, pues inmediatamente se desligó de toda posible responsabilidad derivada de la visita del conde de Selvaflorida, y, como demostrará en su larga trayectoria en la Caja de Quito, ambicioso y calculador. La actuación de Diego Suárez de Figueroa y Fernando García Aguado en los hechos que analizamos fue siempre conjunta y no se produjo ningún tipo de enfrentamiento entre ambos.

\section{El envío de los situados a Cartagena y Santa Marta desde la Caja de Quito}

Desde el año 1672 y hasta 1819, la Caja Real de Quito estuvo obligada a enviar anualmente el situado 4 a los presidios de Cartagena (32.375

3 Ruigómez y Ramos, 2007.

4 «El situado es, jurídicamente, una ayuda vía depósito de capital, que la Corona española instauró hacia finales del siglo XVI para mantener la defensa de las guarniciones con menos recursos económicos, pero que no será hasta el siglo XVIII cuando alcance su máxima expansión y desarrollo, constituyéndose en un aspecto clave de la defensa de América. Económicamente, el situado es una mera transferencia de capital desde una caja matriz a otra subalterna, mientras que administrativamente, no es más que la aportación fijada obligatoriamente sobre una caja matriz que debe sufragar en todo o en parte las tropas de una guarnición, es decir, su componente humano, ... [siendo] el destino último del situado la tropa y su mantenimiento». Serrano, 2006, 80-81. 
pesos) y Santa Marta (12.000 pesos), lo que se compensó con la exención de tener que enviar los excedentes que en ella se produjeran a la Península. José de Munive, miembro del Consejo de Indias, comentaba que en el siglo XVII la Caja de Quito solía tener unos ingresos anuales cercanos a los 110.000 pesos y unos gastos de 50.000 , de lo que resultaba un saldo favorable de en torno a 60.000 pesos, que tenía que remitir íntegramente a España. Por real cédula de 1672 se ordenó que, puesto que las Cajas del Nuevo Reino de Granada no podían mantener los presidios de Cartagena y Santa Marta, se enviara a ellos desde la de Quito 42.375 pesos en concepto de situado, suspendiéndose la remisión de los 60.000 pesos excedentes a España, lo que debería haber supuesto un mayor desahogo para la Caja de Quito. ${ }^{5}$ Hasta 1712 la caja quiteña cumplió con bastante puntualidad esta obligación, pero a partir de ese año la regularidad se quebró. Por su parte, la Caja de Santa Fe, que también tenía que socorrer a los dos presidios, fue mucho más irregular en sus envíos. Veamos cómo se desarrollaron los hechos.

\section{Problemas con el envío del situado en tiempos del presidente Juan de Zozaya (1712-1715)}

En abril de 1712 se reunía la Junta de Real Hacienda de Quito, organismo que se encargaba de la supervisión de la Caja Real y de la gestión de los oficiales reales, ${ }^{6}$ ante la declaración de éstos de que ese año, dada la pésima situación de la Caja, les era imposible remitir el preceptivo situado a Cartagena. En esta primera reunión, además de constatar el problema de insolvencia de la Real Hacienda, se acordó que los oficiales reales, Diego Suárez de Figueroa y Fernando García Aguado, instaran a los curas a pagar inmediatamente las mesadas eclesiásticas ${ }^{7}$ «procediendo por ejecuciones, prisiones y embargos hasta que se consiga su recaudación», para así poder reunir la cantidad necesaria para cumplir con la remisión del situado. Así

5 AGI, Quito, 166, sin f., informe de José de Munive de 14 de abril de 1716.

6 La Junta de Real Hacienda estaba integrada por el presidente Juan de Zozaya, los oidores José Lorente y José de Laysequilla, el fiscal Lorenzo Lastero y los oficiales reales Diego Suárez de Figueroa y Fernando García Aguado. En fechas posteriores se incorporó el oidor Fernando Sierra Osorio.

7 Consideramos que esta medida fue irregular porque lo procedido de las Medias annatas y de las Mesadas eclesiásticas tenía que ser enviado directamente a España y, por lo tanto, no debía ser utilizado en Quito en gastos corrientes, como el situado. 
lo hicieron, recurriendo a los fiadores ${ }^{8} \mathrm{y}$, efectivamente, en ese año 1712 , pese a las reticencias iniciales, se acabaron enviando los correspondientes situados a Cartagena y Santa Marta. ${ }^{9}$

La misma situación se volvió a presentar el año 1713. Cuando en marzo, el presidente Zozaya ordenó el envío del situado, los oficiales reales contestaron que no tenían recursos para hacerlo, lo que nuevamente desembocó en la convocatoria de la Junta de Real Hacienda. En ella, Suárez de Figueroa y García Aguado aseguraron que «en el estado en que se hallaba la Real Caja era imposible el despacho de los situados, respecto de no haber dinero alguno en ella, ni forma de que entre», porque, aunque se habían embargado bienes a algunos deudores, «la total falta de dinero [en la provincia]... motiva el que no se puedan vender [dichos bienes embargados]» ${ }^{10}$ Para demostrar la penuria en que se encontraba la Real Hacienda quiteña, días después presentaron una breve relación de lo que entraba y salía de la Caja anualmente, tomando como fecha de referencia la de $1712 .{ }^{11}$ Esta relación, como veremos más adelante, les pudo haber acarreado graves complicaciones.

A diferencia del año anterior, esta vez la Junta de Real Hacienda no acordó nada y se limitó a traspasar el problema a la Audiencia, que asumió la opinión de Suárez de Figueroa y García Aguado y escribió al virrey de Lima, al que manifestó que «ante la falta de medios de estas Reales Cajas se hacía impracticable la remisión de los situados de Cartagena y Santa Marta». Si lo que esperaban era que la citada autoridad les eximiera de esa contribución, la respuesta de ésta les decepcionaría, pues se limitó a decir «que en el todo, o parte la mayor que se pueda, tenga efecto la remisión de los situados». ${ }^{12}$

Así que otra vez la pelota se encontraba en el tejado de la Junta de Real Hacienda quiteña, que se reunió en octubre de 1713 y solicitó a los oficiales reales que buscaran fondos para cumplir con la obligación del

8 Archivo Nacional del Ecuador (ANE), Real Hacienda, 43 (1677-1714), Libro de la Junta de Real Hacienda (1680-1714), fs. 176 y 177, Juntas de Real Hacienda de 7 y 14 de abril de 1712.

9 Serrano, 2004, 211 y 221.

10 ANE, Real Hacienda, 43 (1677-1714), Libro de la Junta de Real Hacienda (1680-1714), 178, Junta de Real Hacienda de 23 de marzo de 1713.

11 AGI, Quito, 166, sin f., relación de cuentas del año 1712, realizada el 31 de marzo de 1713. Adjuntarán un testimonio de esta relación a su carta al rey de 15 de marzo de 1714.

12 ANE, Real Hacienda, 43 (1677-1714), Libro de la Junta de Real Hacienda a (1680-1714), 179. Estos datos están tomados del acta de la reunión de la Junta de Real Hacienda de 13 de octubre de 1713. 
envío del situado. Estos dijeron que habían mandado cobradores a toda la provincia y que «uniformemente [habían afirmado] no poder ejecutar cobranza alguna por la falta absoluta de plata que hay en ella», que no había compradores para los bienes que se embargaban, que consideraban que no se podía enviar a la cárcel a los deudores porque ésta se llenaría «meses y años» y que tampoco se podía actuar contra los fiadores. La Junta asumió las explicaciones de los encargados de la Caja y decidió escribir al virrey con todos estos argumentos..$^{13}$ No conocemos la respuesta del gobernante, pero sí que ese año 1713 no se enviaron los situados a Cartagena y Santa Marta y que el gobernador de esta última plaza, José Mozo de la Torre, escribió al rey el 16 de diciembre. En esta carta le comunicaba la situación crítica del presidio, lo necesario que era el situado - incluso proponía que se aumentara- y el incumplimiento de Quito.

Como todos los años por las mismas fechas, en marzo de 1714 se volvió a presentar el problema en la Junta de Real Hacienda, esta vez acuciados, por una parte, ante la llegada de unos apoderados de Santa Marta que reclamaban el envío del situado que les correspondía y, por otra, por las cartas del gobernador de Cartagena al presidente en términos parecidos. En la Junta se plantearon nuevas alternativas. En primer lugar, se propuso recurrir al dinero que obraba en poder del oidor Sierra Osorio, encargado de la venta y composición de tierras, pero esta iniciativa se descartó inmediatamente porque se trataba de poca cantidad y porque tenía órdenes de enviar ese dinero directamente a España. Por su parte, los oidores Llorente y Laysequilla tantearon una idea novedosa: que los apoderados de los presidios pudieran «componerse con los deudores, permitiendo efectos de ropa de la tierra» que luego podrían vender en Santa Fe, propuesta que finalmente no se tuvo en cuenta. ${ }^{14} \mathrm{La}$ intervención del presidente Zozaya se centró en el cobro de las deudas contraídas por los corregidores, que ascendían, según sus cálculos, a más de 90.000 pesos. Si en las otras propuestas Suárez de Figueroa y García Aguado no intervinieron, en ésta lo hicieron en el mismo sentido que habían venido haciendo en años anteriores y consideraron imposible el cobro de las deudas a la Real Hacienda en general y de los corregidores en particular por «la insolvencia general ... [y] la suma pobreza de aquella tierra». Insistieron en que no había compradores para los bienes embargados y en que, aunque se vendieran las haciendas, éstas

13 Ibidem.

14 A otras Cajas del Virreinato del Perú se les permitió enviar el situado en dinero y en mercancías. Malamud, 1986, 251. 
estaban tan gravadas con censos que «rara vez resulta cantidad líquida» tras su venta. Pese a estos argumentos el presidente Zozaya les dio el plazo de ocho días para cobrar las deudas de los corregidores y del arrendador de las alcabalas. ${ }^{15}$

Suárez de Figueroa y García Aguado, como era previsible, no pudieron hacer esa cobranza y, ante la presión a que se veían sometidos desde Quito y Lima, decidieron escribir directamente a la Corona para justificar la imposibilidad de remitir, ni siquiera parcialmente, los dos últimos situados a Cartagena y Santa Marta. En este informe de 15 de marzo de 1714 forzosamente tuvieron que ser más explícitos que en la Junta de Real Hacienda a lo hora de explicar los motivos del déficit de la Caja quiteña, que sintetizaban en una primera afirmación: «la salida excede a la entrada», que reforzaban con el envío del pequeño resumen de las cuentas de 1712, hecho en marzo de 1713 para presentar a la Junta de Real Hacienda. En el informe explicaban que la Real Hacienda quiteña no tenía entradas fijas, que el coste de los salarios de los ministros era muy elevado, ${ }^{16}$ que la Caja estaba gravada con una serie de gastos extraordinarios (que no especificaban) por órdenes de Lima y Madrid y que tenían que hacer frente a otros desembolsos por «aderezos y fábricas de iglesias, socorros y gastos de guerra para todos los puertos comarcanos, [y] conducciones de papel sellado y su refrenda». También exponían en su carta el caso de la deuda de 39.000 pesos no abonados por Francisco Meneses Bravo de Saravia del tiempo que había sido corregidor de Riobamba, quien, sin haber saldado dicha cuenta, pasó a ser nombrado presidente de la Audiencia de Santa Fe, posiblemente sin que en el Consejo se tuviera conocimiento de dicha deuda, que ellos consideraban irrecuperable.

Pero por encima de estos motivos, los oficiales reales manifestaban que se encontraba «la imponderable pobreza que se experimenta en todo este reino», debida a que

15 ANE, Real Hacienda, 43 (1677-1714), Libro de la Junta de Real Hacienda (1680-1714), 181, Junta de Real Hacienda de tres de marzo de 1714.

16 Los oficiales reales desglosaban los cargos a cuyos sueldos tenía que hacer frente la Caja: el presidente, Juan de Zozaya, los oidores Cristóbal de Ceballos Morales y Borja, Fernando de Sierra Osorio, José Llorente, José de Laysequilla; el fiscal Lorenzo Lastero de Salazar; el protector con futuro de oidor Esteban de Oláis y Echeverría; el anterior presidente Mateo de la Mata que vivía en Lima y gozaba del salario de oidor desde que dejó la presidencia, pensión que se le había concedido hasta que pasase a España, y, por último, el contador de Bienes de Difuntos Pedro José Bermúdez Becerra. También se esperaba que entraran como oidores Juan Dionisio de Larrea Zurbano y Juan Bautista Sánchez de Orellana, que tenían plaza supernumeraria. 
el comercio que tenía [esta provincia] con el reino del Perú, para donde se conducían los paños que se labraban y otros géneros que se vendían con muy buena cuenta, los cuales en el tiempo presente no tienen valor ninguno, por la abundancia de ropa que ocurre del reino de Francia a todos los puertos del Perú, donde se vende de mucho tiempo a esta parte libremente, con cuyo motivo ha perdido su valor la que se fabricaba en esta provincia, la cual traía dinero a ella, y habiendo éste extraviado su curso para otros reinos, no hay quien por acá lo posea.

Hay que tener en cuenta que la influencia francesa en el Pacífico, que se había iniciado hacia 1685, se afianzó tras la paz de Ryswick en 1697 y se oficializó durante la Guerra de Sucesión española con la real cédula de Felipe V de 11 de enero de 1701, que autorizaba a los franceses a fondear en los puertos de Indias para avituallarse y carenar los barcos. A modo de ejemplo, en 1706 llegaron más de quince navíos a las costas de Chile, Perú y Quito. ${ }^{17}$ Carlos Malamud establece que el periodo de máxima presencia francesa en las costas del Perú fue, precisamente, el comprendido entre 1712 y $1717 . .^{18}$

Si en las Juntas de Real Hacienda celebradas en Quito, la actitud de Suárez de Figueroa y García Aguado fue pasiva, pues se limitaron a insistir en la imposibilidad del envío de los situados sin aportar soluciones, en este escrito al rey sí que propusieron algunas medidas que ellos consideraron realistas y eficaces. La primera fue que todas las encomiendas se agregaran a la corona y que fueran los oficiales reales los encargados de cobrar el tributo de los indios. Con ello se evitaría que los corregidores recurrieran para hacer la cobranza a terceras personas, que usurpaban los tributos de los indios de la corona y los agregaban a las encomiendas; que los indios huyeran ante el acoso al que se veían sometidos por los cobradores y, por último, que la diversidad de tasas que había dejara de producir fraudes y confusión. En segundo lugar, solicitaban licencia para sellar y resellar los papeles oficiales, porque, dada la distancia que les separaba de España, muchas veces no servía el que se enviaba para los años de su concesión. Decían que el que se remitía cada dos años desde Lima con frecuencia sólo servía para un año o menos, lo que obligaba a que tuviera que refrendar dicho papel el juez privativo de este derecho, que era el oidor más antiguo, teniendo ello un coste de escribano y amanuense de cinco pesos de a ocho cada resma. En tercer lugar, sugerían que se enajenase el obraje de Otavalo que se encontraba en manos de la corona y tenía un alto coste de mantenimiento. Y, por último, que se suprimiera el oficio de contador de Bienes de Difuntos que ocupaba

17 Arosemena, 1992, 62.

18 Malamud, 1986, 223. 
Pedro José Bermúdez Becerra, porque no lo consideraban de utilidad y tenía un salario muy elevado (3.000 pesos) que, aunque debía cobrarlo del propio Juzgado de Bienes de Difuntos, en su título se establecía que si este Juzgado no tuviera la cantidad necesaria, como de hecho sucedía, las Cajas Reales debían satisfacérselo. ${ }^{19}$

Evidentemente, esta carta de Suárez de Figueroa y García Aguado a Madrid no significó que se diera por zanjada la cuestión en Quito. En la Junta de Real Hacienda celebrada el 20 de marzo de 1714 se trató el tema de la relación de deudas que los responsables de la Caja habían presentado y de la afirmación que hacían de que se estaban ocupando de enviar a la cárcel a los deudores y sus fiadores - medida que les parecía totalmente ineficaz, en lo que coincidía el oidor Laysequilla-. Pero los oficiales reales también pusieron encima de la mesa un tema que aparecía en su escrito al rey y que hasta ahora no se había planteado en la Junta, aunque aquí lo hicieron con un matiz distinto. Si al monarca le habían comunicado que una de las cargas de la Caja era el elevado número de miembros de la Audiencia a los que había que pagar salario, en la Junta expusieron - seguramente para congraciarse con ese Tribunal- que el pago de estos salarios debía preceder al de los situados, según una real cédula que no citaban,

mayormente cuando todos [los ministros] se hallan con crecidas obligaciones y notoria falta de dinero y medios por la cortedad del salario, en tierra que ha padecido el exceso en todos los precios de las cosas respecto del tiempo en que se hizo asignación de los salarios a estas plazas, siendo los más ínfimos que otra Audiencia alguna de este reino.

argumento que, como es de suponer, nadie contradijo. Finalmente, se decidió, a instancia del presidente Zozaya, que en quince días los corregidores o sus fiadores entregaran lo que debían, ya que con esas cantidades habría suficiente dinero para enviar el situado. El resto de los miembros de la Junta consideraron que el plazo era impracticable, aunque en el ánimo de todos los ministros estaba el que se enviara el situado lo antes posible. ${ }^{20}$

En esta misma Junta, el oidor Laysequilla abrió una nueva vía: el cobro de los valimientos de encomiendas que, según él, suponían la mayor

19 AGI, Quito, 166, sin f., los oficiales reales al rey sobre la situación de la Real Hacienda quiteña de 15 de marzo de 1714. En el escrito se hace referencia al envío de un informe similar al Tribunal de Cuentas de Lima, que desconocemos, así como su posible respuesta.

20 ANE, Real Hacienda, 43 (1677-1714), libro de la Junta de Real Hacienda (1680-1714), 187, Junta de Real Hacienda de 20 de marzo de 1714. 
parte de los 200.000 pesos que se adeudaban a la Caja Real. Esta propuesta dio lugar a que el 24 de marzo de 1714 se reuniera la Junta de Valimiento y promulgara un auto en el que ordenaba que, en el plazo de quince días, Suárez de Figueroa y García Aguado cobraran dichos valimientos a los corregidores y encomenderos, y si no lo hacían el presidente encargaría a otra persona su percepción, y amenazaba con pasar a la corona las encomiendas cuyos titulares no presentaran confirmación. ${ }^{21}$

Pese a los apremiantes plazos de las Juntas de Real Hacienda y de Valimientos los oficiales reales no pudieron ejecutar las cobranzas y nada nuevo se hizo en relación con el envío del situado a Cartagena y Santa Marta. El presidente Zozaya se encontraba al final de su mandato y había concluido la visita que el conde de Selvaflorida había hecho a la Caja de Quito, en la que el contador Diego Suárez de Figueroa salió condenado y suspendido de su cargo entre julio de 1714 y marzo de 1715. Pero, el 27 de julio de 1715, juraba su cargo ante el Cabildo de la ciudad el nuevo presidente, Santiago de Larraín, ${ }^{22}$ que daría un nuevo impulso al tema.

\section{Actuaciones del presidente Santiago de Larraín en relación con el envío del situado (1715-1716)}

Larraín inmediatamente se ocupó del envío de los situados ante la llegada de una real cédula de 13 de octubre de 1714 en la que la Corona, que había recibido la queja del gobernador de Santa Marta ante el incumplimiento de los correspondientes a los años 1713 y 1714, le apremiaba para que la Caja de Quito cumpliera con su obligación..$^{23}$ Por ello, el pre-

21 ANE, Autos acordados, 2, v. 2 (1684-1717), 159, auto de la Junta de Valimiento de 24 de marzo de 1714 .

22 ANE, Real Hacienda, 47 (1713-1721), v. III (Libro del contador de 1715), 47, título de presidente de la Audiencia de Quito para Santiago de Larraín de diez de agosto de 1710. Pagó la media annata el 28 de julio de 1715. Archivo Metropolitano de Quito (AMQ), Actas, 1715, 16, Juramento del cargo de presidente en el Cabildo de 27 de julio de 1715 .

23 ANE, Cedularios, 7 (1704-1733), v. 1704-1733, docs. 10 y 24, fs. 55 y 99, la real cédula de 13 de octubre de 1714 dirigida al presidente, Audiencia y oficiales reales de Quito también decía que en esta ocasión no se debían descontar, como era habitual, los 500 pesos en concepto de conducción del situado. ANE, Fondo Especial, 10 (1723-1727), 107, con otra real cédula enviada en la misma fecha al gobernador de Santa Marta, en la que no se accedía a su petición de aumento en la cantidad del situado, y éste inmediatamente envió apoderados a Quito para reclamar los dos situados que se especificaban y los correspondientes a los años 1715 y 1716, que tampoco se habían librado. Esta cédula se recibió en Santa Marta el seis de marzo de 1715 y suponemos que poco después lo haría en Quito la que se había enviado al presidente, Audiencia y oficiales reales. 
sidente emitió un auto el 13 de agosto de 1715 para que Suárez de Figueroa y García Aguado le informasen de la situación en que se encontraba la remisión de los situados a Cartagena y Santa Marta y las razones del retraso en el envío. Aquéllos respondieron que se debía a «la suma escasez de la Real Caja, ocasionada por la extrema y general inopia de estos reinos, haciéndose por ella incobrables los efectos de Hacienda Real» y que para este año sólo habían podido reunir 4.289 pesos, de los 42.375 preceptivos. En otro auto de 20 de febrero de 1716, Larraín ordenó a los oficiales reales entregar al apoderado del presidio de Santa Marta los 12.000 pesos que solicitaba, sacándolos «de cualesquier efectos que hubiese en la Caja, aunque fuesen pertenecientes al valimiento, con cargo de reintegrarse luego que se recauden los demás efectos». Finalmente, el seis de mayo de 1716 se entregaron a dicho apoderado los 12.000 pesos correspondientes al año 1716, pero no la cantidad que se debía por los tres anteriores situados..$^{24}$

Por tanto, el presidente Larraín se enfrentó enérgicamente a la resignación y desidia con que Suárez de Figueroa y García Aguado parecían afrontar las dificultades que atravesaba la Real Hacienda en el territorio quiteño, y fue más allá. En su siguiente paso solicitó a los encargados de la Caja una relación de las numerosas deudas que se arrastraban en ella, encargo que éstos cumplieron con la demora acostumbrada. El 25 de septiembre de 1716 Larraín escribía a Madrid para informar al Consejo de cuáles habían sido sus pasos hasta ese momento en relación con el envío de los situados a Cartagena y Santa Marta. ${ }^{25}$

\section{La respuesta de Madrid}

Entre 1714 y 1718 llegaron a Madrid tres comunicaciones relacionadas con las dificultades en el envío de los situados desde Quito: la carta del gobernador de Santa Marta, José Mozo de la Torre, de 16 de diciem-

24 AGI, Quito, 128, exp. 52, 557. Todos estos acontecimientos se encuentran citados en el escrito de Larraín al rey de 25 de septiembre de 1716 y en el testimonio que adjuntaba de 14 de septiembre del mismo año.

25 Ibidem, 562, Consejo de cinco de febrero de 1718. En esa fecha se recibió en el Consejo y se pasó al fiscal, que el 30 de marzo de 1718 pasó a manos de la Secretaría por ser cuestión de Real Hacienda, que contestó «no corresponde en este caso más que decir al presidente que se esperan los autos que ofrece». 
bre de 1713; el informe de Suárez de Figueroa y García Aguado de 15 de marzo de 1714 y la carta del presidente Larraín de 25 de septiembre de 1716. Y todas ellas tuvieron respuesta, eso sí, con bastante dilación en el tiempo.

La carta de José Mozo de la Torre dio lugar, como hemos visto, a las dos reales cédulas de 13 de octubre de 1714 dirigidas a las autoridades quiteñas y al gobernador de Santa Marta y tuvo como efecto el envío del situado a Santa Marta correspondiente al año 1716. De la carta de Larraín de 25 de septiembre de 1716 derivó la real cédula de cuatro de abril de 1718, recordando al presidente la obligación de enviar los situados a Cartagena y Santa Marta. ${ }^{26}$

Fue el informe de los oficiales reales de marzo de 1714 -al que acompañaba un testimonio con la relación de las cuentas del año 1712-el que más impacto y repercusiones tuvo en Madrid, transcendiendo ampliamente el tema de los situados, que pasó a un segundo plano. En el Consejo se tomó conciencia del mal estado en que se encontraba la Real Hacienda en el distrito de la Audiencia de Quito - territorio que hasta entonces no había dado problemas graves en materia hacendística-, del que se hizo responsable, como veremos, a la mala gestión de los oficiales reales y no a la crisis de la región.

Antes de tomar ninguna decisión, el Consejo solicitó tres informes: uno al fiscal del Consejo, que emitió el 28 de noviembre de $1715 ;{ }^{27}$ otro a la Contaduría, de 14 de febrero de $1716,{ }^{28}$ y uno último al consejero José de Munive, ${ }^{29}$ de 14 de abril de $1716 .{ }^{30}$ De estos tres pareceres podemos decir que su contenido es desigual, fundamentalmente porque el de la Contaduría es mucho más escueto y ligero y se limita a comentar el testimonio de las cuentas de 1712 que enviaron Suárez de Figueroa y García Aguado junto a su escrito, mientras que los del fiscal y de José de Munive son extensos, reflexionados, e intentan llegar a la raíz del problema sin olvidar los detalles.

26 ANE, Cedularios, 6 (1700-1720), doc. 129, 314 (540).

27 AGI, Quito, 166, sin f.

28 Ibidem y AGI, Quito, 407, informe 670.

29 José de Munive era hijo de Lope Antonio de Munive, presidente de Quito entre 1678 y 1689. Sin duda, se recabó su opinión por el conocimiento de la realidad quiteña que tenía. 30 AGI, Quito, 166, sin f. 


\section{Análisis de las razones dadas por los oficiales reales sobre el declive de la Real Hacienda quiteña}

Como hemos comentado, el informe de Suárez de Figueroa y García Aguado consideraba que la principal causa de ese declive de la Hacienda quiteña se encontraba en la ruina que había supuesto para el comercio de paños, y en consecuencia de su producción, la entrada de textiles franceses. El fiscal del Consejo no daba ninguna credibilidad a este argumento pues consideraba que los paños franceses eran de una calidad superior a la de los quiteños y, por lo tanto, no constituían realmente una competencia para éstos y, además, el distrito contaba con otros recursos, que no especificaba. Por su parte, José de Munive, mejor conocedor de la situación, sí pensaba que la introducción de ropa de Francia pudo perjudicar seriamente las bases de la economía quiteña y decía que «aunque el señor fiscal no se conforma con esta razón, tengo por cierto puede serlo bastante para que se experimente la pobreza que refieren». Y consideraba «no solo probable sino certísimo el descaecimiento que habrá padecido la ropa de esta tierra, por la misma razón de ser la de Francia más noble y preciosa, divirtiéndose en ella los caudales que habían de aprovecharse en este comercio». Lo que no tenía tan claro era que esta crisis del comercio de paños afectara, como decían los oficiales reales, tan gravemente a la disminución de los ingresos fiscales porque «las rentas reales [no consistían] en la fábrica ni ventas de los paños, sino en otros,... [de lo que] se sigue la nulidad de esta conjetura o sofisma». Pensaba que la única Caja que se debería ver afectada por la caída del comercio de paños quiteños sería la de Lima por el descenso que se produciría en los derechos de alcabala. En cualquier caso, Munive creía que Suárez de Figueroa y García Aguado dramatizaban en exceso la pobreza de la región.

Respecto a la afirmación de los oficiales reales de que no había dinero en la región y, por lo tanto, no se compraban los bienes embargados ni los cargos públicos, el fiscal tampoco lo consideró razón suficiente y pensaba que tenía que haber «hombres de caudal» que se hicieran cargo de ellos.

En cuanto a que la Caja tenía que satisfacer el salario de los muchos ministros de la Audiencia, el fiscal del Consejo opinaba que los oficiales reales exageraban en este punto porque en su relación incluían no sólo a los ministros en ejercicio sino también a los supernumerarios que no gozaban de salario. Munive decía que, efectivamente, ésta podía ser una carga 
importante, pero que llevaba aparejada la cobranza de la media annata de todos esos puestos, lo que era un ingreso considerable, que Suárez de Figueroa y García Aguado ni siquiera mencionaban.

Por otra parte, los oficiales reales habían informado de que les era imposible cobrar lo que se adeudaba de la Caja, especialmente de los corregidores. A la hora de opinar sobre este tema en Madrid se tuvo presente una carta del contador de Bienes de Difuntos en Quito, Pedro José Bermúdez Becerra, de 20 de septiembre de 1714, en la que decía - y el fiscal creyóque los oficiales reales «se tiene entendido están culpablemente sin cobrar» las deudas a los corregidores por «fin y contemplaciones particulares» y que, incluso, el propio contador Diego Suárez de Figueroa, pese a deber más de 40.000 pesos como consecuencia de la visita del conde de Selvaflorida, seguía manteniendo sus bienes. ${ }^{31}$

Respecto de la deuda de 39.000 pesos que había dejado Francisco Meneses Bravo de Saravia, del tiempo que fue corregidor de Riobamba, el fiscal decía que este asunto ya se había tratado en el Consejo independientemente y se había dado la providencia correspondiente en contra del deudor, presidente de la Audiencia de Santa Fe entre 1712 y $1715 .{ }^{32}$

\section{Análisis de las propuestas de los oficiales reales para mejorar la Real Hacienda quiteña}

Suárez de Figueroa y García Aguado proponían en su informe que sería conveniente que se agregaran todas las encomiendas a la corona y que fueran ellos mismos, y no los corregidores y sus tenientes, los encargados de cobrar los tributos de los indios. Sobre este punto el fiscal del Consejo estaba en absoluto desacuerdo y pensaba que detrás de él, «el verdadero fin

31 AGI, Quito, 108, 427, recordemos que los oficiales reales proponían suprimir el oficio de contador de Bienes de Difuntos por ser gravoso para la Real Hacienda. Bermúdez Becerra, en esta misma carta, también acusó al tesorero Fernando García Aguado de vivir en unas casas embargadas, lo que le valió a éste una amonestación y una multa. El contenido de esta carta lo conocemos por una minuta de consulta del Consejo de 27 de febrero de 1717.

32 ANE, Cedularios, 6 (1700-1720), doc. 97, 259 (442) y AGI, Quito, 133, exp. 82, 312. Pese a esta afirmación, posteriormente, el dos de febrero de 1716, se emitió una real cédula en que se condenaba a los oficiales reales suspendiéndoles el sueldo por no haber cobrado dicha deuda y no haber hecho efectivas las fianzas. La cédula llegó a Quito el ocho de abril de 1718 y no se cumplió pues su contenido afectaba a los oficiales reales que se debían haber ocupado de su cobranza, es decir, el tesorero Jacinto Salazar y Betancourt, que ya había fallecido, y Diego Suárez de Figueroa, que ya estaba suspendido de su oficio de contador desde enero de 1718. 
de estos oficiales es poner debajo de su mano todo el caudal de los tributos para disponer a su arbitrio». Por otra parte, opinaba que se evitarían los fraudes y confusión que los oficiales reales comentaban en su informe por la diversidad de tasas tributarias, cobrando a los indios en su lugar de residencia y no en el de origen, como se venía haciendo.

Otra propuesta de Suárez de Figueroa y García Aguado fue el que se les diera licencia para sellar y resellar los papeles oficiales, lo que el fiscal tampoco consideró necesario pues, aunque en otras regiones los oficiales reales dispusieran del sello, desconocía la razón de por qué no lo tenían los de Quito, y «se deberá buscar en la Secretaría la orden que sobre esto hubiere». En su defecto, se tendría que ordenar al virrey de Lima que remitiera el papel de manera que «llegue en tiempo oportuno de que pueda servir enteramente en los años de su concesión». El gasto de cinco pesos por resma le parecía «excesivo, y [...] sería bastante la mitad y algo menos». Munive coincidía con el fiscal.

Los gestores de la Caja quiteña también consideraron que el obraje de Otavalo era muy gravoso para la Real Hacienda. El fiscal pidió que aclararan este punto, pues tal y como aparecía en el informe de aquéllos la redacción era confusa y no hacían una propuesta clara, no sabiendo si lo que pretendían era que «se extinga o abandone este obraje, o de que se mejore su administración y arrendamiento».

La propuesta de los oficiales reales de que se suprimiera el oficio de contador de Bienes de Difuntos fue la única que tanto el fiscal como Munive consideraron oportuna, ya que ambos opinaban que era innecesario y, sobre todo, muy poco rentable para la Corona, pues la venta del oficio se había hecho en 8.000 pesos y el salario que le correspondía era de 3.000 y, además, se le había concedido la posibilidad de traspasarlo a quien casara con una de sus hijas. Ambos pensaban que a Bermúdez Becerra se le debía devolver la cantidad en que lo había comprado.

\section{Análisis de las cuentas del año 1712 presentadas por Suárez de Figueroa y García Aguado}

Pero realmente, como ya hemos dicho, lo que puso en entredicho la gestión de los oficiales reales fue el breve testimonio de las cuentas del año 1712, en el que tanto el físcal del Consejo, como la Contaduría y José de Munive, coincidieron en que era absolutamente lamentable. 
El fiscal fue el primero en detectar los graves problemas contables del extracto de las cuentas que enviaron, lo que le llevó a denunciar «la simulación, falacia y mal disimulado artificio con que está formado». Decía que en el testimonio sólo figuraba lo que entró en la Caja y «no consta, como debía, lo que debió entrar, con que no se puede conocer si, por su omisión, contemplación o malicia, se ha dejado de cobrar alguna cantidad», además no se sacaban al margen, y por lo tanto no se sumaban, todas las cantidades que se habían cobrado. Para el fiscal la afirmación de que la mayoría de los ramos tuvieran una entrada incierta era «insustancial y falaz», y detectó que las cantidades asignadas a los varios ramos no correspondían a los mismos años, incluso a veces se incluían entradas de varias fechas o de años muy atrasados, «pudiéndose presumir sin temeridad que [los oficiales reales] escogerían en cada ramo de Real Hacienda el año o años de menos entrada», con lo que coincidirá más tarde la Contaduría. Además, según el fiscal, en esta cuenta se daban muchos ramos por perdidos sin más razón que en el año en cuestión no se hubieran producido entradas por esos conceptos, o que éstas hubieran sido muy pequeñas, lo que le llevaba a considerar que «aunque sea cierto que en aquel año o años no produjesen nada o produjesen poco, no hay fundamento que prive de la esperanza de que en otros años produzcan más».

La Contaduría del Consejo también emitió una opinión muy desfavorable a las cuentas presentadas, sobre las que decía que si todos los ramos tuvieran unos ingresos tan inciertos como aseguraban deberían elaborar un quinquenio «para que, compensadas las mayores ventajas de unos años, con las disminuciones de los otros, se infiriese prudencialmente lo que corresponda a solo uno». Y, por encima de todo, «se arguye evidentemente el gran arte con que para oscurecer la verdad se viste la confusión».

Las palabras de José de Munive sobre este extracto de cuentas siguen la misma línea que los anteriores:

sobran presunciones para calificar por viciosos todos sus motivos, y aun por afectados sus esfuerzos, siendo no pequeña la de confundir el efecto contingente con el descaecido, pues lo uno, por su propia significación, puede ser más de lo que se espera y lo otro supone ser menos de lo que se debe.

Pero los tres informes no se quedaron sólo en las cuestiones generales, sino que descendieron al detalle y analizaron las cantidades que Suárez de Figueroa y García Aguado habían consignado en cada uno de los ramos 
de su extracto de cuentas del año 1712, tanto de los ingresos como de los gastos, y especialmente de los primeros.

Así, en cuanto a los ingresos por alcabalas, que los oficiales reales habían considerado inciertos, el fiscal decía que en el extracto aparecía un ingreso por este concepto de 14.000 pesos que, al no estar consignado al margen, no había sido contabilizado. Munive opinaba que este ramo corría por arrendamiento y que, por lo tanto, sus ingresos debían ser fijos.

El Estanco de naipes era otro de los ramos que Suárez de Figueroa y García Aguado daban por perdidos. El fiscal no creía que «el vicio del juego» se hubiera acabado en aquella provincia, por lo que pensaba que lo que sucedía era que se estaban introduciendo barajas extranjeras de contrabando, «de que resulta cargo a estos oficiales». Munive coincidía en esta apreciación y planteaba además la sospecha de que se hubiera establecido una fábrica de naipes en la provincia.

El ingreso más importante de la Caja quiteña se correspondía con el ramo de los Tributos y la Contaduría consideraba que Suárez de Figueroa y García Aguado habían consignado ingresos menores de los reales. Munive comentaba que este ramo corría por arrendamiento y, por lo tanto, sus ingresos no podían ser inciertos; que en la Audiencia de Quito no se había producido una disminución en el número de indios como había sucedido en otras provincias a consecuencia del trabajo minero, por lo que esta jurisdicción «siempre ha sido por esta parte envidiada de las demás». Además, puesto que no se había hecho nueva numeración de indios, no habían podido cambiar las tasas.

En esta misma línea estaría el ramo de Condenaciones del Consejo, en el que Munive se extrañaba de la no inclusión en las cuentas de la multa que se le impuso al presidente Zozaya en 1711 por haber contraído matrimonio sin licencia. Sobre el de Quintos de oro y plata, el consejero decía que los encargados de la Caja debían tener un mayor cuidado «comisando todas aquellas porciones que entran y salen en esa ciudad sin quintar». Y en cuanto al de Vacantes de encomiendas el fiscal pensaba que, aunque en el año 1712 sólo se hubiera producido un pequeño ingreso, no significaba que «no fuera posible que haya [uno mayor] en adelante» y Munive que si había encomiendas tenía que haber vacantes, y ponía el ejemplo de un caso concreto para demostrar que efectivamente se debieron producir entradas en este ramo.

Había otra serie de conceptos que Suárez de Figueroa y García Aguado consideraron nulos, en lo que coincidía el consejero Munive. En 
este grupo estarían los de Azogues, Bula de la Santa Cruzada, Composiciones de tierras, Expolios episcopales y el Obraje de Otavalo. Munive daba la razón a los oficiales reales en el caso de los azogues porque en la región no había minas de plata; en el de las Composiciones porque era un ramo separado de las Cajas y para su cobranza había un ministro específico que tenía que enviar el dinero recaudado directamente a España, y que las dificultades por las que pasaba el obraje de Otavalo se debían «haber procedido en sus principios de la poca aplicación de estos ministros o de sus antecesores, teniendo por dificultoso su remedio viciado una vez la causa, y por de mayor interés a la Real Hacienda el que este obraje no corra por cuenta de su majestad». La Contaduría no estaba de acuerdo en considerar estos ramos como nulos, ni otros sobre los que Munive no se pronunciaba (Composiciones de indultos, Composiciones de obrajes, Donativos graciosos, Real Hacienda y Vacantes de obispados).

Finalmente, había otro grupo de ramos que Suárez de Figueroa y García Aguado habían declarado como que no tenían ingresos o con ingresos muy bajos que tuvieron distintas críticas desde la Contaduría o el consejero Munive. Así, respecto de las Mesadas eclesiásticas, Munive decía que unos años compensarían con otros. En los de Novenos reales y Tercias partes de encomiendas, la Contaduría consideraba que los oficiales reales habían consignado ingresos menores a los reales. Munive tampoco creía que el ramo de Oficios vendibles hubiera experimentado una baja tan considerable como afirmaban los encargados de la Caja, pues siempre solían rematarlos los «vecinos acomodados», y éstos no se habían visto afectados por la crisis. Asimismo, el consejero opinaba que, pese a que los oficiales reales consideraban el ramo de Pólvora como corto y contingente, había un gasto continuo y homogéneo pues se utilizaba fundamentalmente para los fuegos artificiales de las fiestas que se celebraban. En cuanto al ramo de Pulperías, Munive decía que en ellas se vendían alimentos y que su comercio no tenía nada que ver con el descenso del comercio de paños.

Si el principal rubro de entradas en la Caja era el ramo de Tributos, la salida más importante correspondía a los Salarios de los ministros de la Audiencia, de cuyo exceso se habían quejado Suárez de Figueroa y García Aguado. Para contradecir esta opinión, el fiscal opinaba que éstos, erróneamente, «consideran como si fuesen perpetuos y fijos los salarios temporales o vitalicios de los ministros supernumerarios, que entonces había, que cada año y cada día pueden cesar por muerte, ascenso u otros muchos motivos». Munive no consideraba importante el argumento de los oficiales rea- 
les en el sentido que eran muchos porque esta circunstancia se había dado en otros tiempos y, concretamente, decía que eran los mismos que en el año 1692, y en aquella ocasión no se tuvo que recurrir a las Mesadas eclesiásticas y Medias annatas, como se había hecho ahora. Recordemos que lo recaudado por estos dos conceptos debía enviarse íntegramente a España y no podía ser utilizado en gastos corrientes en Quito, como eran los Salarios de los ministros.

Respecto del gasto en Misiones de San Francisco, Munive decía que los oficiales reales consignaban cantidades por este concepto y, sin embargo, se daba la circunstancia de que en la corte de Madrid se encontraba un apoderado franciscano que se estaba quejando precisamente de la falta de asistencia de la Caja de Quito.

El consejero tenía sus dudas sobre algunas de las Pensiones que los oficiales reales consignaban como pagadas. En concreto se refería a la de Manuel Zapata, pues hacía poco tiempo se había despachado en el Consejo una queja de retraso de la misma. Por otra parte, había dos pensiones muy antiguas: las de Manuel de Aguiar de 1689 y Teresa María del Castillo Campero de 1680 , que no se sabía a quién se pagaban y «siendo tan antiguas las mercedes se puede inferir hayan fallecido».

Suárez de Figueroa y García Aguado se habían quejado de que la Caja estaba gravada con una cantidad importante de Gastos extraordinarios, que se ordenaban desde Madrid o desde Lima. El fiscal del Consejo opinaba que si esto fuera cierto, debían haber replicado vivamente cuando el virrey les hubiera mandado pagar estas libranzas extraordinarias, arguyendo que tenían unas prioridades insoslayables, como la de los situados. Como vemos, ramo por ramo, el fiscal, la Contaduría y el consejero Munive fueron desmontando las cuentas que habían presentado los oficiales reales quiteños.

Pasando a las sumas de estos ramos, el fiscal decía que Suárez de Figueroa y García Aguado consideraban que la Caja tenía un déficit anual de 12.194 pesos, por lo que no podían pagar el situado que ascendía a 42.375 pesos, sin embargo, sí lo incorporaban entre las salidas de la Caja. El fiscal opinaba también que si efectivamente no lo habían pagado en dos años debían sobrar unos 30.000 pesos, ${ }^{33}$ que se suponía, por lo que decían los propios oficiales reales, habían servido para pagar libranzas extraordinarias, «por el grande interés que de ello sacarán, prefiriendo estas pagas,

33 Incluye también la cantidad correspondiente a las Mesadas eclesiásticas y Medias annatas que, debiéndose enviar a España, no se había hecho. 
por sus injustas ganancias, a los situados de los presidios y demás cargas reales de aquellas Cajas, que notoriamente tienen el primer lugar».

Según los cálculos de la Contaduría - descontando de las entradas las Medias annatas y Mesadas eclesiásticas y contabilizando la entrega de los 42.375 pesos correspondientes a los situados-, la Caja de Quito sólo tendría un déficit de 11.572 pesos, pero si no se hacían esos ajustes, tendría un superávit de más de 40.000 pesos, que desde luego hubieran permitido pagar los situados.

Así vemos que donde las cuentas presentadas por Suárez de Figueroa y García Aguado chirriaban era en la contabilidad, por un lado, de las Mesadas eclesiásticas y Medias annatas y, por otro, de los Situados. El fiscal decía que los oficiales reales no sumaban a la cuenta final de los ingresos las Mesadas y Annatas, con el argumento de que por ley estos dos ramos tenían que ser remitidos a España, sin embargo, ellos mismos opinaban que habían tenido que hacer uso de ellos en Quito para pagar las cargas fijas de la Caja. La contradicción se agudiza cuando los administradores sí que incluían y contabilizaban como salida el salario del juez de Media annata. En cuanto a los situados, los oficiales reales los incluían como gasto realmente ejecutado, cuando, precisamente, todo el problema se había originado por no poder pagarlos.

\section{Propuestas del fiscal del Consejo, de la Contaduría y de Munive}

A la vista de lo expuesto anteriormente, en lo que coincidían los tres informantes del escrito que venimos analizando es en que Suárez de Figueroa y García Aguado tenían que ser sancionados por su pésima gestión, reflejada fundamentalmente en el extracto de las cuentas. Así, el fiscal decía que «se deberá advertir a estos oficiales con una severísima reprensión, enviando copia de ella a la Audiencia para que sea notoria y les cause alguna mortificación que sirva de enmienda».

Los tres no sólo detectaron los problemas, también plantearon soluciones. El fiscal consideró que era

necesaria una exacta y rigurosa visita de aquellas Cajas, [...] para restaurar la Real Hacienda, que tan perdida se halla en aquellas provincias, y corregir a ministros que tan olvidada tienen la obligación de sus oficios y la importancia de que la Real Hacienda esté desempeñada y abundante, pues de ella depende la defensa y conservación de los reinos. 
La Contaduría, por su parte, decía que del extracto de cuentas se infería un desorden total en la administración de la Real Hacienda quiteña, y para comprobar el argumento de Suárez de Figueroa y García Aguado de que las salidas superaban a las entradas, no eran suficientes las cuentas enviadas, por lo que se les debía solicitar un quinquenio, en el que se reflejaran las deudas y las diligencias que se estaban realizando para cobrarlas. ${ }^{34}$

Munive no se quedó atrás en palabras que califican lo mal que estaba la administración de la Real Hacienda quiteña, y elevaba el tiro, al descalificar también a la Audiencia:

De todo lo expresado se manifiesta un desbarato universal en que se halla aquella provincia, falta de medios por sobra de inútiles ministros, fuera del orden regular las principales materias que debieran tocar al presidente y Audiencia, y las comunican al Consejo los ministros de la inferior clase, explicando con este desbarato la disonancia con que se halla el gobierno de aquella provincia.

Estaba de acuerdo con el fiscal en la necesidad de una visita de la Caja y que de hallar culpados a Suárez de Figueroa y García Aguado, como supondría que lo haría, se les debía remover de sus oficios. Además se debían poner en cobro todos los ramos perdidos y hacer numeración de indios, lo que era necesario para arreglar el ramo de tributos. En otro orden de cosas, Munive también consideraba que se debía mejorar el salario de los oficiales reales hasta los 800 pesos, pues el que percibían en estos momentos -500 pesos_- era demasiado bajo.

\section{La propuesta de visita a la Caja Real de Quito}

Estos tres informes, y sobre todo los del fiscal y de José de Munive, convencieron al Consejo de que se debía hacer la visita por ellos propuesta, y en su reunión de dos de mayo de 1716 solicitó a Francisco Castejón elaborar la consulta correspondiente para nombrar como visitador al presidente de la Audiencia, que debía ser ministro togado, restableciéndose la costumbre de que los presidentes de Quito tuvieran esta categoría. El borrador de la consulta se pasó al fiscal el cinco de mayo y éste sugirió que asesorase al presidente el oidor José Llorente, pues el resto de los ministros

34 AGI, Quito 166, sin f., certificación de 14 de febrero de 1716. La Contaduría también informó al Consejo de que obraba en su poder un testimonio de las cuentas del quinquenio que se hizo de los años 1687 a 1691, en que hubo un pequeño superávit de unos 2.100 pesos. 
eran inadecuados..$^{35} \mathrm{El} 23$ de diciembre de 1716 se presentó ante el Consejo una nueva minuta de consulta en la que se incluyeron todos estos puntos. ${ }^{36}$

Paralelamente, el 17 de diciembre de 1716, se presentó el borrador de «Instrucción de los puntos principales sobre que se halla bien informado S.M. estar gravemente culpados los oficiales de la Real Hacienda de Quito, que ha de tener muy presentes el presidente de aquella Real Audiencia, don Santiago de Larraín, visitador nombrado de las Reales Cajas mencionadas, para aplicarse con toda actividad, integridad y celo del real servicio». ${ }^{37}$

En ella se acusaba directamente a Suárez de Figueroa y García Aguado, sin lugar a dudas, de haber faltado «tan torpemente no sólo a la verdad, sino al respeto debido a su majestad, que parece le imaginan totalmente ciego y ajeno de la inteligencia y noticias de su Real Hacienda y aún de la razón natural, que por si sola descubre la crasa malicia de su informe».

Según esta instrucción, el visitador tendría que cobrar una serie de deudas - de casi 200.000 pesos - de las que el Consejo tenía conocimiento, ${ }^{38}$ investigar seriamente el por qué se había dejado de cumplir con el envío de los situados a Cartagena y Santa Marta y no se habían enviado a España los caudales procedentes de las Mesadas eclesiásticas y Medias annatas. También debía averiguar la situación en la que se encontraba el obraje de Otavalo, el por qué los precios de los oficios eran tan bajos «especialmente habiendo hombres de considerable caudal en aquella provincia» y la razón por la que los oficiales reales no habían estorbado la introducción del comercio de ropas de Francia, «pues no pudieran ejecutarse estas introducciones sin conocida tolerancia suya». Asimismo, debía analizar el por qué Suárez de Figueroa y García Aguado afirmaban que la Hacienda real dependía tanto del comercio, cuando el grueso de los ingresos de la Caja eran los tributos de los indios.

35 AGI, Quito, 108, exp. 28, 317, propuesta del fiscal de cinco de junio de 1716. Los oidores Cevallos y Borja, Sierra Osorio y Laysequilla y el fiscal Lastero tenían procesos abiertos, el protector Oláis no tenía los estudios y títulos suficientes y los dos oidores supernumerarios, Sánchez de Orellana y Larrea Zurbano, eran naturales de Quito y tampoco tenían estudios de leyes.

36 Ibidem, 382.

37 Se haría visita de todo el tiempo en que no se hubieren inspeccionado las Cajas, sin tener en cuenta las visitas que se hubieran hecho por comisión de los virreyes (se refiere concretamente a la de Selvaflorida, realizada entre 1711 y 1714 por encargo del virrey-obispo Ladrón de Guevara). El salario del visitador provendría de los bienes de los culpables.

38 Las de los corregidores de Riobamba (Francisco Meneses - 39.000 pesos- y Antonio Muñoz - 20.000 pesos-), de Latacunga (el corregidor era hermano de Juan Bautista Sánchez de Orellana), de Quito (amigo y compadre del tesorero Fernando García Aguado — 40.000 pesos-), de Pedro Infantas (primo del tesorero - 49.000 pesos-) y los alcances de Diego Suárez de Figueroa en la visita realizada por el conde de Selvaflorida -40.000 pesos-. 
Pero, sobre todo, el visitador debía hacer

gravísimo cargo a estos oficiales, de haber fundado su informe de la quiebra y atraso de todos los ramos de Real Hacienda en un testimonio evidentemente artificioso, insuficiente y malicioso, [...] ni consta [...], como debía, lo que por razón de cada ramo debió haber entrado en las Reales Cajas, sino solamente lo que dicen entró, encubriendo con este claro artificio sus omisiones y fraudes cometidos en la recaudación, pues no constando lo que debió entrar en las Cajas no se puede saber lo que han dejado de recaudar, contra la obligación de sus oficios.

Y, siguiendo en este caso el informe de la Contaduría, el presidentevisitador debía averiguar qué había sucedido con los 30.000 pesos que esta institución deducía que había de excedentes, «si los han usurpado con frívolos pretextos y astucias o los tienen divertidos en sus injustos y prohibidos comercios y tratos, o si, como dan a entender, los han consumido en pagar libramientos extraordinarios».

Finalmente, si resultaran culpables Suárez de Figueroa y García Aguado, como no podía ser de otra forma, se les suspendería de sus cargos, embargarían sus bienes y se nombrarían interinos. ${ }^{39}$

Tras los informes que hemos analizado, el borrador de la instrucción de la visita, y la consulta del Consejo de 23 de diciembre de 1716 se hubiera tenido que promulgar la real cédula correspondiente ordenando la visita de la Caja. Pero no fue así, pues, en el mes de mayo de 1717, se hacía efectiva la decisión de extinguir la Audiencia quiteña y crear el virreinato del Nuevo Reino de Granada, a donde pasaría a depender la jurisdicción de Quito. ${ }^{40}$ Lo más sorprendente es que, diez días después, se emitió una real cédula dirigida a los oficiales reales Diego Suárez de Figueroa y Fernando García Aguado, en donde, además de comunicarles la extinción de la Audiencia y la erección del nuevo virreinato, simplemente se les recordaba la obligación de enviar los situados a Cartagena y Santa Marta y las cuentas de la Caja del año 1717 y en adelante a Santa Fe. ${ }^{41}$ Así que no sólo se les mantenía en el cargo, sino que ni siquiera recibieron una pequeña amonestación por su actividad al frente de la Caja, cuando meses antes era segura su destitución.

39 AGI, Quito, 108, 383, borrador de Instrucción de la visita de 17 de diciembre de 1716.

40 ANE, Cedularios, 6 (1700-1720), 112, 302 (504), real cédula a la Audiencia de 17 de mayo de 1717. Se recibió en Quito en octubre de 1718.

41 AGI, Santa Fe, 369, exp. 78, 1, real cédula a los oficiales reales de 27 de mayo de 1717. 


\section{Conclusiones}

A la vista de los hechos, podemos concluir que la gestión de los oficiales reales de Quito, Diego Suárez de Figueroa y Fernando García Aguado, en los años que nos ocupan, fue francamente desastrosa. Escribieron al rey en marzo de 1714 pensando que éste y el Consejo comprenderían la pésima situación de la Real Hacienda quiteña y se les aliviaría del pago del situado y lo único que consiguieron fue que el Consejo reaccionara proponiendo una exhaustiva visita de la Caja, de la que los oficiales reales no hubieran podido salir, en ningún caso, bien parados. Pero si en este primer momento podemos decir que sus expectativas e, incluso, su continuidad en los oficios de contador y tesorero, se vieron seriamente amenazadas, poco después tuvieron la inmensa fortuna de que la extinción de la Audiencia quiteña y la erección del virreinato de Santa Fe paralizaran la visita y ellos salieran impunes.

La mala gestión de Suárez de Figueroa y García Aguado hizo que ninguno de los argumentos que utilizaron para justificar las dificultades de la Caja de Quito fuera tenido en cuenta en España, cuando pensamos que la caída de la producción obrajera, la escasez de moneda en la región y, sobre todo, la introducción de textiles franceses en el comercio del Pacífico afectaron seriamente a la economía quiteña y, por ende, a la Real Hacienda. Y en este último punto, la corona española tuvo su responsabilidad.

Recibido el 26 de enero de 2011 Aceptado el 5 de mayo de 2011

\section{Bibliografía}

Arosemena Arosemena, Guillermo: El comercio exterior del Ecuador. Vol. I: Periodo colonial: La Audiencia de Quito, Guayaquil, El Autor, 1992.

Malamud Rikles, Carlos D.: Cádiz y Saint-Malo en el comercio colonial peruano (1698-1725), Cádiz, Diputación Provincial, 1986.

Ruigómez Gómez, Carmen y Ramos Gómez, Luis: «De la legalidad al fraude: la compra, acceso, dejación y renuncia al cargo de contador de Quito por José Suárez de Figueroa (1688-1748)», en Ruiz Rivera, Julián y Sanz Tapia, Ángel (coords.): La venta de cargos y el ejercicio del poder en Indias, León, Universidad de León, 2007, 111-138. 
Serrano Alvarez, José Manuel: Fortificaciones y tropas. El gasto militar en Tierra Firme, 1700-1788, Sevilla, Diputación Provincial de Sevilla / Universidad de Sevilla / CSIC, 2004.

Serrano Álvarez, «Economía, rentas y situados en Cartagena de Indias, 17611800», Anuario de Estudios Americanos, LXIII, 2, Sevilla, 2006, 75-96. 